\title{
Optimization of the Geometric Parameters of the Thermal Insulation of the Heating System by Using Multi-Pipe Circular Thermal Insulation
}

\author{
Tomasz Janusz TELESZEWSKI ${ }^{1 *}$, Dorota Anna KRAWCZYK ${ }^{2}$, Antonio RODERO ${ }^{3}$ \\ 1,2 Department of HVAC Engineering, Bialystok University of Technology, Bialystok 15-351, Poland \\ ${ }^{3}$ University of Cordoba, School of Engineering Sciences of Belmez, Cordoba, Spain
}

\begin{abstract}
The publication presents a design solution for circular multi-pipe thermal insulation and an example of an existing heating installation consisting of six individual heating pipes in the building of the Bialystok University of Technology. In the paper, the arrangement of six heating system pipes in circular thermal insulation was designed in such a way that one heating pipe is centrally located in the circular thermal insulation, the other five heating pipes are located at the vertices of a regular pentagon inside the circular thermal insulation. Heat loss calculations were made using the Boundary Elements Method (BEM) with the actual boundary conditions in the room where the existing heating installation is located. Additionally, the ecological effect was determined in the form of reduction of pollutants emitted into the atmosphere resulting from heat losses for the developed multi-pipe thermal insulation. The calculation results showed a significant reduction in heat losses as a result of the use of multi-pipe thermal insulation in relation to the existing single heating installation. The use of multi-pipe insulation undoubtedly follows the trend of energy-saving heat transport and is an alternative to the commonly used single pipes.
\end{abstract}

Keywords - Heat losses; heat transport; multi-tube thermal insulation; pre-insulated pipes

\begin{tabular}{|lll|}
\hline \multicolumn{2}{|l}{ Nomenclature } & $\mathrm{m}$ \\
$d$ & diameter of the heating pipe & $\mathrm{m}$ \\
$D$ & diameter of thermal insulation for a single pipe & $\mathrm{m}$ \\
$D^{\prime}$ & diameter of multi-pipe thermal insulation for variant A & $\mathrm{m}$ \\
$D^{\prime}$ & diameter of multi-pipe thermal insulation for variant B & $\mathrm{kg} / \mathrm{year}$ \\
$\Delta E_{m}$ & reduction of pollutants emission & $\mathrm{GJ}$ \\
$E$ & annual energy resulting from heat loss & $\mathrm{g} / \mathrm{GJ}$ \\
$E_{f}$ & the emission factor of pollutants into the atmosphere & $\mathrm{W} / \mathrm{m}^{2} / \mathrm{K}$ \\
$h$ & heat transfer coefficient & $\mathrm{W} / \mathrm{m} / \mathrm{K}$ \\
$k$ & thermal conductivity & $\mathrm{m}$ \\
$L$ & pipe length & $\mathrm{W} / \mathrm{m}$ \\
$q$ & unit heat flux & $\mathrm{W} / \mathrm{m}^{2}$ \\
\hline
\end{tabular}

* Corresponding author.

E-mail address: t.teleszewski@pb.edu.pl 


\begin{tabular}{|lll|}
\hline$T$ & $\begin{array}{l}\text { temperature } \\
\text { the distance between the pipes in variants A and B and the distance between } \\
\text { the pipe and the external wall of thermal insulation for variant A } \\
\text { distance between the pipe and the external wall of thermal insulation for } \\
\text { variant B }\end{array}$ & $\mathrm{m}$ \\
$x, y$ & Cartesian coordinates & $\mathrm{m}$ \\
Subscripts & & \\
$\mathrm{A}$ & variant A & \\
$\mathrm{amb}$ & ambient \\
$\mathrm{B}$ & variant B & \\
$i$ & pipe number & \\
$j$ & variant designation (A or B) \\
$\mathrm{R}$ & return pipe & \\
$\mathrm{S}$ & supply pipe & \\
\hline
\end{tabular}

\section{INTRODUCTION}

For years improvements possible to apply in heating and domestic hot water networks have been analysed to provide higher energy efficiency of systems and achieve a reduction in pollutants emission.

Some researchers analysed new solutions or methodologies for estimation of heat generation and distribution. Volkova et al. [1] proposed to supply buildings from new cogeneration plants using renewable energy sources and heat pump technologies. Vigants et al. [2] studied energy usage in DHS in dependence on flow and temperature conditions in networks. Stennikov at al [3] showed results of optimization of heat supply radius for DHS in a town in Russia. Ruseljuk et al. [4] studied legal, climate and economic factors to highlight weak points in DHS in Estonia and Serbia networks. Authors noted the need of government support, through regulations and financial aids, that could increase efficiency of solutions. Pourbozorgi Langroudi et al. [5] reviewed different methods of predictive maintenance and the compatibility to apply on a DH network. Al-Barqawi and Zayed [6] classified three main groups of factors influencing DHN efficiency changes in time as: physical factors connected with pipes (like age material, diameter, isolation etc.) environmental factors (for example climate, solid type, pipes location) and operation parameters (like fluid quality, flow velocity etc.).

Designing a new heat source for a building or modernizing an existing heat source involves determining the heat demand for central heating purposes and the heat demand for hot water heating, taking into account losses in heat transport. By reducing heat losses in heat transport through pipes, the power of the heat source can be reduced, which translates into the reduction of pollutants emitted to the atmosphere from the heat source and the operating costs of the heat source.

The improvement of thermal insulation of heat transporting pipes can be related to both external heating networks and heating systems inside the building. The amount of heat losses depends on the climate in which the heating network is located [7], [8] and the operating parameters of the heating networks, such as the temperature of the heating medium [9]-[12].

Modifications aimed at improving the thermal insulation of heating pipes usually consist in the use of new insulation materials with a lower thermal conductivity coefficient or a change in the geometry of the thermal insulation cross-section. Changing the geometry of the thermal 
insulation may consist in: adding an additional layer of thermal insulation (so-called heating pipes with thermal insulation in the 'plus' version [13]), using new shapes in cross-sections of thermal insulation [12], [14], [15] and locating many pipes in a common thermal insulation [14], [16].

According to the 'A Framework Strategy for a Resilient Energy Union with a ForwardLooking Climate Change Policy', improving the energy efficiency of heating systems is a priority policy task for the European Union. In the Directive of the European Parliament and of the Council (EU) of December 11, 2018, it was stated that: 'Improving energy efficiency throughout the full energy chain, including energy generation, transmission, distribution and end-use, will benefit the environment, improve air quality and public health, reduce greenhouse gas emissions...' [17]. One of the ways to improve the energy efficiency of the energy sector in line with the Directive [17] is the modernization of heat transport pipes.

The aim of this study is to propose a solution for circular multi-pipe thermal insulation in which six heating installation pipes are located. The concept of multi-pipe thermal insulation was made on the basis of the existing heating installation in the underground part of the building of the Faculty of Civil Engineering and Environmental Sciences of the Bialystok University of Technology. In order to compare the heat losses of the multi-pipe thermal insulation with the existing heating pipes, numerical calculations were performed using the Boundary Elements Method (BEM). It should be noted here that in practice the number of pipes in a common thermal insulation is usually limited to two pipes [13].

\section{The Concept of Multi-Pipe Circular Insulation on the Basis of THE EXISTING HEATING INSTALLATION}

For the transport of heat in heating systems, single heating pipes with round thermal insulations are most often used (Fig. 1).

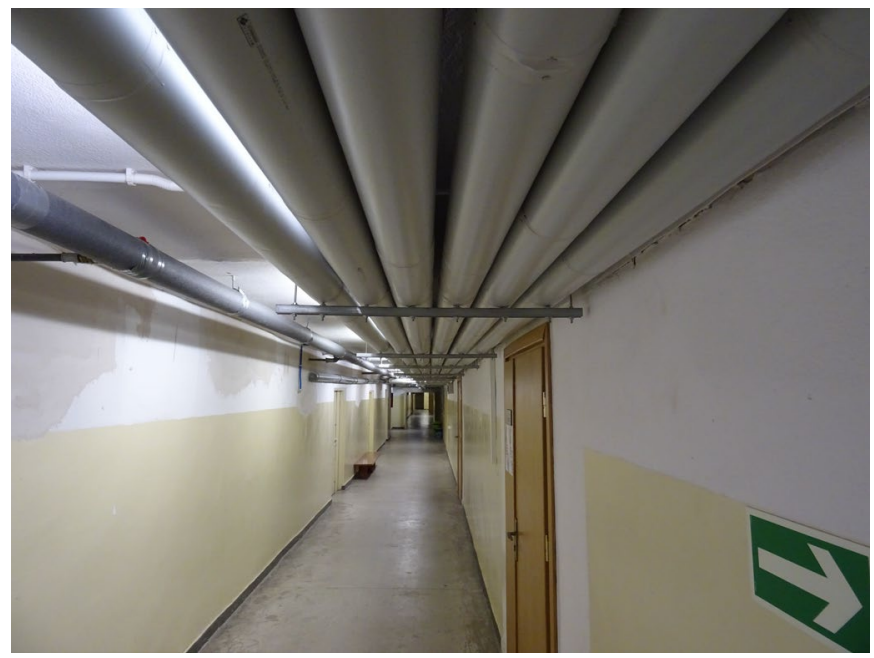

Fig. 1. The analysed heating system in the building of the Bialystok University of Technology, consisting of six single heating pipes. 


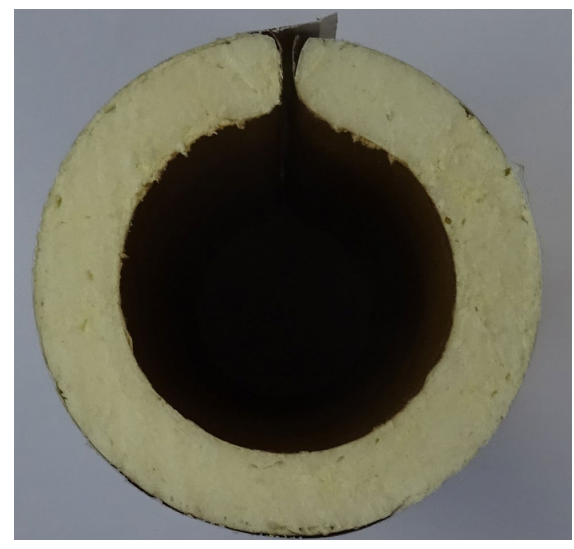

(a)

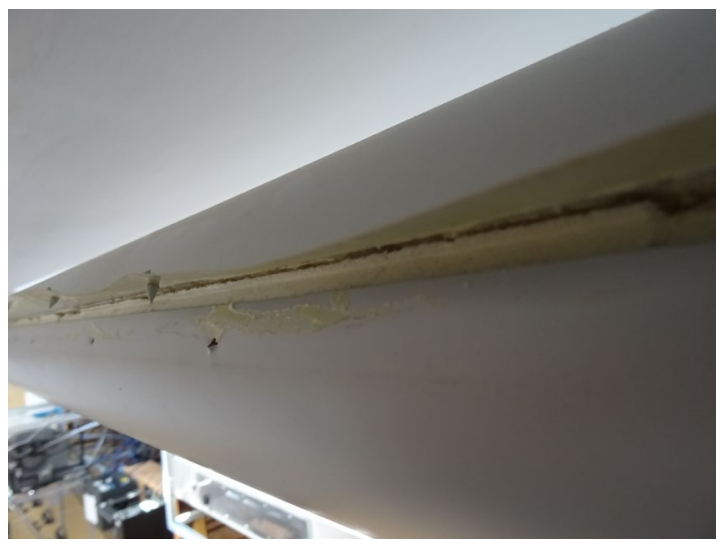

(b)

Fig. 2. Longitudinal connections of a typical thermal insulation of a single conductor, which may cause linear thermal bridges: a) Cross-section of the thermal insulation; b) View of the longitudinal connection of the thermal insulation.

The main advantage of circular thermal insulation on single heating pipes is the simplicity of installation. The disadvantages of thermal insulation of circular individual pipes are high consumption of thermal insulation material around the heating pipe and thermal bridges that may appear, which result from the method of thermal insulation installation after the heating installation is completed. The simplest installation of thermal insulation on a heating pipe made is to apply thermal insulation through an indentation along the thermal insulation Fig. 2(a) and 2(b). After applying thermal insulation to the pipe, the longitudinal indentation is usually sealed with plastic tape. This type of connection of the edges of the thermal insulation can cause a longitudinal thermal bridge. Thermal bridges generate additional heat losses in heating pipes.

The solution to the problem of linear thermal bridges in heating systems can be prefabricated heating pipe systems in pre-insulated technology. Additionally, by using multitube thermal insulation, the amount of insulation material can be reduced compared to circular thermal insulation used in single heating pipes. The publication presents the technical solution of round multi-pipe thermal insulation as an alternative to six thermal insulation of single pipes of a heating system. The geometry of the presented circular multi-pipe thermal insulation is designed in such a way that one of the supply pipes is placed centrally in a regular pentagon, while the other five pipes are placed at the vertices of a regular pentagon. The distances between heating pipes in multi-pipe thermal insulation were adopted, similarly to standard twin pipe pipes, and for the presented example the distance is equal to $20 \mathrm{~mm}$. Two variants were adopted due to the distances between the piping and the external wall of thermal insulation: in the first standard solution, the distance between the pipe and the external surface of the thermal insulation was assumed to be equal to the distance between the pipe $w=20 \mathrm{~mm}$ (version A, Fig. 3(b)), in the second case (version B, Fig. 3(c)), the distance between the pipes and the outer wall of the thermal insulation was assumed to be equal to the thickness of the thermal insulation of a single heating pipe $w^{\prime}=(D-d) / 2$, Fig. 3(a) and 3(c). Table 1 presents the main features of the geometry of single pipes and multi-pipe insulation in A and B versions. The total thermal insulation area in the cross-section of the multi-pipe thermal insulation in variants A and B is respectively lower by $37.6 \%$ and $20.1 \%$ compared to the thermal insulation surface area of six single pipes. 
(a)

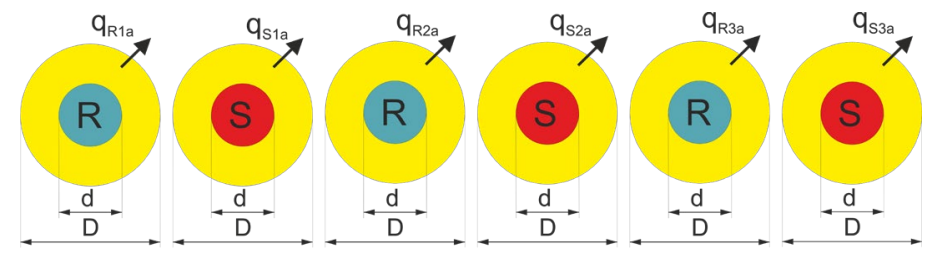

(b)
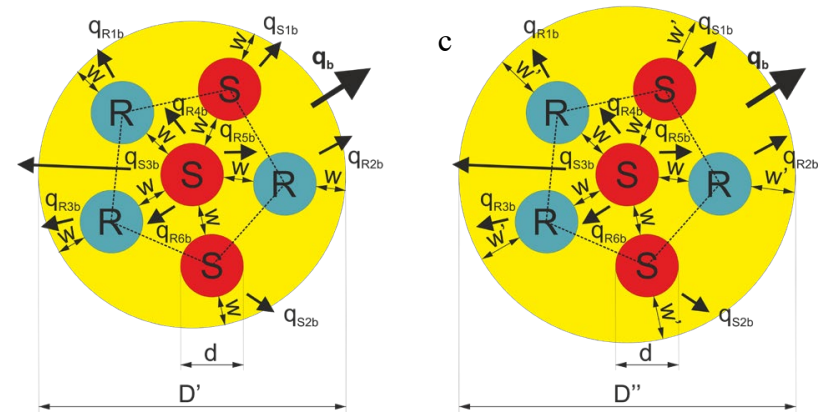

Fig. 3. Geometry and boundary conditions (S-supply pipe, R-return pipe): a) Six single pipes of the heating system; b) Multi-pipe thermal insulation (variant A), where ' $w$ ' is the distance between the pipes and the distance between the pipe and the external wall of thermal insulation; c) Multi-pipe thermal insulation (variant B), where w is the distance between the pipes and $w^{\prime}$ is the distance between the pipe and the external wall of thermal insulation.

TABLE 1. GEOMETRY OF THE ANALYSED VARIANTS OF THERMAL INSULATION

\begin{tabular}{|c|c|c|c|c|c|c|}
\hline $\begin{array}{l}\text { Description of the } \\
\text { thermal insulation } \\
\text { variant }\end{array}$ & $\begin{array}{l}\text { Heat pipe } \\
\text { diameters } \\
d\end{array}$ & $\begin{array}{l}\text { Minimum } \\
\text { distance } \\
\text { between } \\
\text { pipes } w^{*}\end{array}$ & $\begin{array}{l}\text { The minimum } \\
\text { thickness of the } \\
\text { thermal insulation } \\
\text { between the pipe and } \\
\text { the external wall of the } \\
\text { thermal insulation } \\
w, w^{*}\end{array}$ & $\begin{array}{l}\text { Thermal } \\
\text { insulation } \\
\text { diameter } \\
D, D, D \text {, }\end{array}$ & $\begin{array}{l}\text { Thermal } \\
\text { insulation } \\
\text { field }\end{array}$ & $\begin{array}{l}\text { Percentage } \\
\text { change in } \\
\text { the area of } \\
\text { thermal } \\
\text { insulation in } \\
\text { relation to } \\
\text { single pipes }\end{array}$ \\
\hline- & $\mathrm{m}$ & $\mathrm{m}$ & $\mathrm{m}$ & $\mathrm{m}$ & $\mathrm{m}^{2}$ & $\%$ \\
\hline six single pipes & 0.04830 & 0.02000 & 0.03085 & 0.11000 & 0.04603 & - \\
\hline $\begin{array}{l}\text { multi-pipe thermal } \\
\text { insulation, version A }\end{array}$ & 0.04830 & 0.02000 & 0.03085 & 0.22490 & 0.02873 & 37.6 \\
\hline $\begin{array}{l}\text { multi-pipe thermal } \\
\text { insulation, version B }\end{array}$ & 0.04830 & 0.02000 & 0.02000 & 0.24660 & 0.03677 & 20.1 \\
\hline
\end{tabular}

*Note: Fig. 3(b) and 3(c)

\section{Methodology of Determining Heat losses Through Multi-Pipe THERMAL INSULATION}

The following chapter presents the methodology for determining heat losses through single pipes and multi-pipe thermal insulation. In order to determine the heat losses in single pipes, the theoretical solution of thermal conductivity in circular pipes was used:

$$
q_{\mathrm{Sia}}=\frac{\left(T_{\mathrm{S}}-T_{\mathrm{amb}}\right) \pi}{\left(\frac{1}{2 k} \ln \left(\frac{D_{i}}{d_{i}}\right)+\frac{1}{h D_{i}}\right)}[\mathrm{W} / \mathrm{m}],
$$




$$
q_{\mathrm{Ria}}=\frac{\left(T_{\mathrm{R}}-T_{\mathrm{amb}}\right) \pi}{\left(\frac{1}{2 k} \ln \left(\frac{D_{i}}{d_{i}}\right)+\frac{1}{h D_{i}}\right)}[\mathrm{W} / \mathrm{m}]
$$

where

$q_{\mathrm{Sia}}, q_{\mathrm{RSia}}$ Heat losses through the supply and return conduit, respectively;

$D_{i} \quad$ Diameter of the thermal insulation;

$d_{i} \quad$ Diameter of the heat pipe;

$h \quad$ Heat transfer coefficient of $25 \mathrm{~W} / \mathrm{m}^{2} / \mathrm{K}$;

$k \quad$ Thermal conductivity coefficient of the thermal insulation;

$T_{\mathrm{S}}, T_{\mathrm{R}}$ Temperature of the heating medium of the supply and return heating pipe, respectively;

$T_{\mathrm{amb}} \quad$ Ambient temperature and $i$ is the number of the pipe.

The total heat losses through six single pipes were determined according to the formula Fig. 3:

$$
q_{\mathrm{a}}=q_{\mathrm{Sla}}+q_{\mathrm{S} 2 a}+q_{\mathrm{S} 3 \mathrm{a}}+q_{\mathrm{R} 1 \mathrm{a}}+q_{\mathrm{R} 2 \mathrm{a}}+q_{\mathrm{R} 3 \mathrm{a}}[\mathrm{W} / \mathrm{m}] .
$$

Determination of heat losses in multi-pipe insulation was performed using the Boundary Element Method. For this purpose, the differential equation of thermal conductivity in the cross-sectional area of multi-pipe insulation was solved:

$$
\frac{\partial^{2} T}{\partial x^{2}}+\frac{\partial^{2} T}{\partial y^{2}}=0, \quad q_{x}=-k \frac{\partial T}{\partial x}, \quad q_{y}=-k \frac{\partial T}{\partial y},
$$

where $x$ and $y$ are Cartesian coordinates in the cross-sectional area of multi-pipe thermal insulation.

Robin's condition was adopted for the calculations:

$$
q^{\prime}=-k \frac{\partial T}{\partial n}=h\left(T-T_{\mathrm{amb}}\right)\left[\mathrm{W} / \mathrm{m}^{2}\right]
$$

Unit heat losses for multi-pipe thermal insulation were determined from the heat flux balance (Fig. 3(b) and 3(c)):

$$
q_{\mathrm{b}}=q_{\mathrm{S} 1 \mathrm{~b}}+q_{\mathrm{S} 2 \mathrm{~b}}+q_{\mathrm{S} 3 \mathrm{~b}}+q_{\mathrm{R} 1 \mathrm{~b}}-q_{\mathrm{R} 4 \mathrm{~b}}+q_{\mathrm{R} 2 \mathrm{~b}}-q_{\mathrm{R} 5 \mathrm{~b}}+q_{\mathrm{R} 3 \mathrm{~b}}-q_{\mathrm{R} 6 \mathrm{~b}}[\mathrm{~W} / \mathrm{m}],
$$

where the negative heat fluxes mean the heat transferred from the supply pipe $\mathrm{S}$ to the return pipe R (Fig. 3(b), 3(c)).

The Boundary Element Method is used in many thermal and flow problems [18], [19]. Details of the BEM algorithm are presented in the literature [20]. For the simulation, a Fortran program was written. The verification of the Boundary Element Method is presented in the following works [15]. For the numerical BEM simulations, the boundary of a crosssection of 3000 elements was adopted.

\section{RESUlts AND Discussion}

Fig. 4 shows a diagram of unit heat losses in the ambient temperature range from 0 to $20{ }^{\circ} \mathrm{C}$ for six single pipes determined from the analytical Eq. (1) and unit heat losses of multi-pipe thermal insulation determined by the BEM method. Average heat losses turned out to be $57 \%$ and $67 \%$ lower, respectively for variants $\mathrm{A}$ and $\mathrm{B}$, compared to single thermal insulations. Multi-tube thermal insulation is characterized by a significant reduction in heat loss compared to single ducts. In the works [14], [21], the use of twin pipes allowed to reduce heat losses by 
about $32 \%$ to $50 \%$ compared to single pipes, depending on the thickness of the insulation. It should be noted that there are various versions of the standard insulation and the so-called 'plus' [13] with a thickened layer of thermal insulation. In the case of triple pre-insulated pipes, heat losses are approximately $42 \%$ to $55 \%$ [14], [16] lower than in the case of single pre-insulated pipes. It can be seen that the more pipes are located in a common multi-pipe insulation, the greater the reduction of heat losses in relation to single heating pipes.

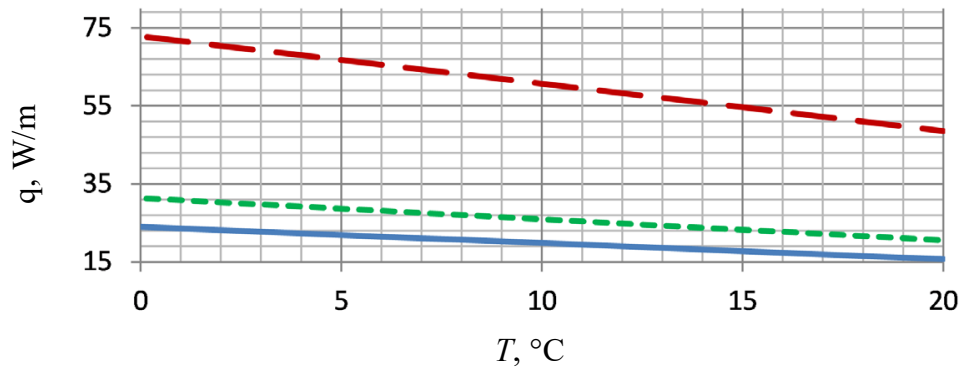

- six single pipes in separate circular thermal insulation
- six pipes in a common circular thermal insulation (case A)
six pipes in a common circular thermal insulation (case B)

Fig. 4. Unit heat losses in the ambient temperature $T$ in six single heating pipes and in two variants of multi-pipe thermal insulation (cases A and B).

Fig. 5(a) and 5(b) show the temperature and heat flux density fields, respectively, for variants $A$ and $B$ of multi-pipe thermal insulation for an ambient temperature of $8{ }^{\circ} \mathrm{C}$. In the case of variant A, significant values of the heat flux density between the supply pipes and the external walls of thermal insulation can be noticed, which can be eliminated by adding an additional thermal insulation field in the cross-sectional area (option B), i.e. increasing the diameter of the multi-pipe circular insulation.

The heat source in the building of the Bialystok University of Technology is powered by a coal-fired CHP plant. It should be noted here that the actual heat source, in line with the trends of climate neutrality, should be replaced by a renewable energy source. Reducing heat losses in the internal heating system allows to reduce the heat demand for the entire building, and thus reduces the emission of pollutants into the atmosphere. Table 2 shows the reduction of pollutants emitted to the atmosphere by the use of multi-pipe thermal insulation in relation to single pipes. The following pollutants emitted into the atmosphere were assumed for the calculations [22], [23]: nitrogen oxides $\left(\mathrm{NO}_{\mathrm{X}}\right)$, carbon monoxide $(\mathrm{CO})$, non-methane volatile organic compounds (NMVOC), sulphur oxides $\left(\mathrm{SO}_{\mathrm{X}}\right)$, total suspended particles (TSP), particulate matter $\left(\mathrm{PM}_{10}\right.$ and $\left.\mathrm{PM}_{2.5}\right)$, carbon dioxide $\left(\mathrm{CO}_{2}\right)$ and methane $\left(\mathrm{CH}_{4}\right)$.

The reduction of pollutants $\left(\Delta E_{\mathrm{m}}\right)$ emitted into the atmosphere resulting from heat losses by the application of variants $\mathrm{A}$ and $\mathrm{B}$ in relation to single pipes on the tested section of the installation was determined according to the following formula:

$$
\Delta E_{m}=\left(E_{a}-E_{b(j)}\right) \cdot E_{f}[\mathrm{~kg} / \text { year }],
$$

where 
$E_{f} \quad$ Pollutant emission coefficient according to [20, 21];

$E_{a} \quad$ Annual energy for heat loss in the existing six single heating pipes;

$E_{b(j)} \quad$ Annual energy for heat loss in multi-pipe thermal insulation in variants $\mathrm{A}$ and $\mathrm{B},(j=A$ or $j=B)$.

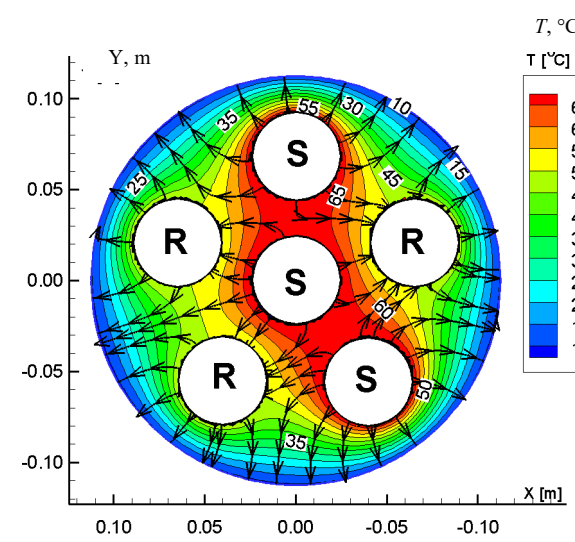

(a)

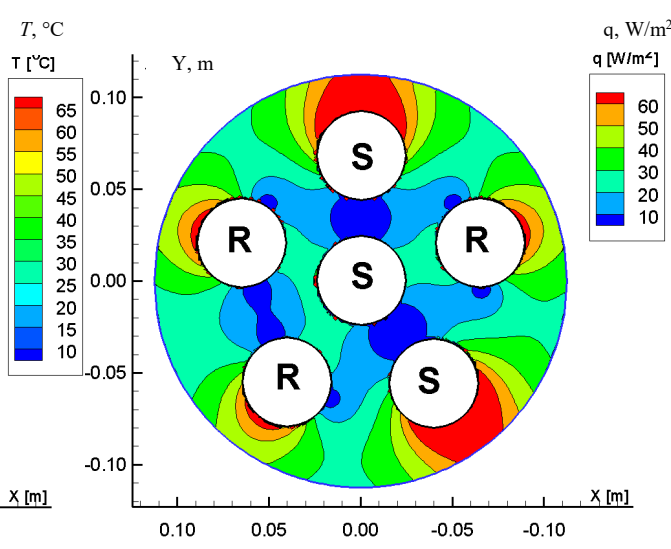

(b)

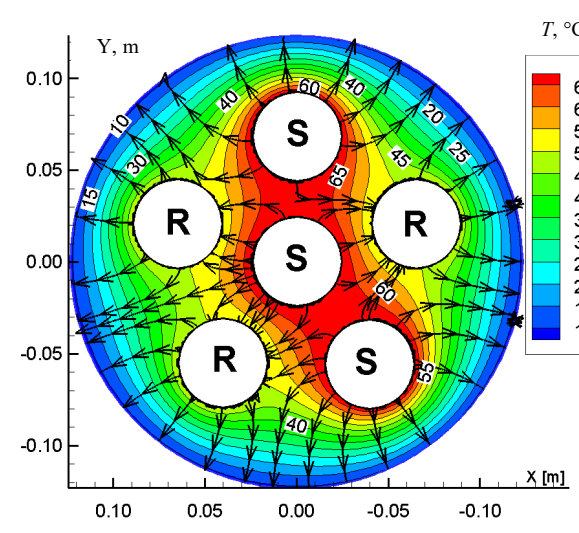

(c)

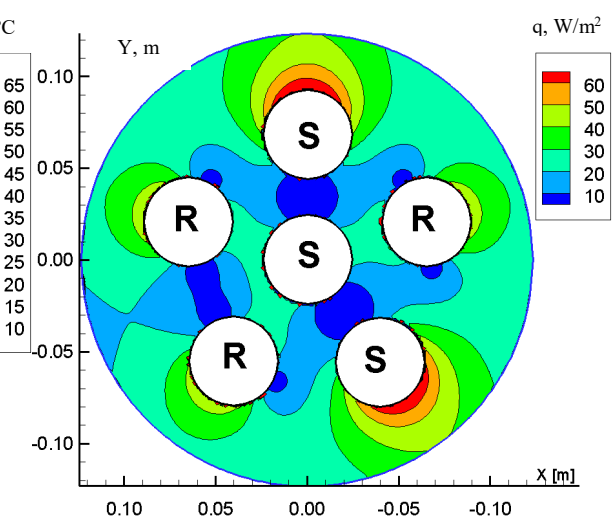

(d)

Fig. 5. Temperature field in the cross-section of multi-pipe thermal insulation for variant A (a) and variant B (c) and the distribution of flux density in the cross-section of multi-pipe thermal insulation for variant A (b) and variant B (d).

The annual energy for heat $\operatorname{loss} E_{a, b(A), b(B)}$ is determined as the product of the pipe length, time and unit heat losses.

Table 2 shows the calculation results of the annual emission of pollutants resulting from heat losses for six single pipes $E_{a} E_{f}$ and multi-pipe thermal insulation in variants $\mathrm{A} E_{b(A)} E_{f}$ and $\mathrm{B} E_{b(B)} E_{f}$, for an assumed length of $40 \mathrm{~m}$, and an ambient temperature of $8^{\circ} \mathrm{C}$ during the heating season (255 days). Additionally, the study determined the unit reduction of pollutants per meter of installation length $\Delta E_{a-b(A)} / L, \Delta E_{a-b(B)} / L$, so that other scientists and engineers could refer to the obtained results and compare their results. Pollutants emitted to the atmosphere from heat losses in the tested heating installation turned out to be on average about two and three times smaller for variants A and B, respectively, compared to single heating pipes. 
TABle 2. AnNual EMissions of Pollutants due to HeAt Losses Determined For VARIANTS OF SiX Single PIPES AND MUlti-PIPE THERMAL INSUlATION IN VARIANTS A AND B

\begin{tabular}{|c|c|c|c|c|c|c|c|c|}
\hline \multirow[b]{2}{*}{ Pollutant } & \multirow{2}{*}{$\begin{array}{l}E_{f}, \\
\mathbf{g} / \mathbf{G J}\end{array}$} & \multirow{2}{*}{$\begin{array}{l}E_{a} E_{f}, \\
\mathrm{~kg} / \text { year }\end{array}$} & \multicolumn{3}{|l|}{ Case A } & \multicolumn{3}{|l|}{ Case B } \\
\hline & & & $\begin{array}{l}E_{b(A)} E_{f}, \\
\text { kg/year }\end{array}$ & $\begin{array}{l}\Delta E_{m(A)}, \\
\mathrm{kg} / \text { year }\end{array}$ & $\begin{array}{l}\Delta E_{m(A)} / L \\
\text { kg/year/m }\end{array}$ & $\begin{array}{l}E_{b(B)} E_{f}, \\
\mathbf{k g} / \text { year }\end{array}$ & $\begin{array}{l}\Delta E_{m(B)}, \\
\mathrm{kg} / \text { year }\end{array}$ & $\begin{array}{l}\Delta E_{m(B)} L, \\
\mathrm{~kg} / \text { year/m }\end{array}$ \\
\hline $\mathrm{NO}_{\mathrm{x}}$ & 209.0 & 11.616 & 5.0 & 6.6 & 0.166 & 3.807 & 7.8 & 0.195 \\
\hline $\mathrm{CO}$ & 8.7 & 0.484 & 0.207 & 0.276 & 0.007 & 0.158 & 0.3 & 0.008 \\
\hline NMVOC & 1.0 & 0.056 & 0.024 & 0.032 & 0.001 & 0.018 & 0.0 & 0.001 \\
\hline $\mathrm{SO}_{\mathrm{x}}$ & 820 & 45.6 & 19.5 & 26.1 & 0.65 & 14.9 & 30.6 & 0.766 \\
\hline TSP & 11.4 & 0.634 & 0.271 & 0.362 & 0.009 & 0.208 & 0.4 & 0.011 \\
\hline $\mathrm{PM}_{10}$ & 7.7 & 0.428 & 0.183 & 0.245 & 0.006 & 0.140 & 0.3 & 0.007 \\
\hline $\mathrm{PM}_{2.5}$ & 3.4 & 0.189 & 0.081 & 0.108 & 0.003 & 0.062 & 0.1 & 0.003 \\
\hline $\mathrm{CO}_{2}$ & 98300 & 5463.5 & 2340.0 & 3123.5 & 78 & 1790.5 & 3673.1 & 91.827 \\
\hline $\mathrm{CH}_{4}$ & 1 & 0.056 & 0.024 & 0.032 & 0.001 & 0.018 & 0.0 & 0.001 \\
\hline
\end{tabular}

\section{Conclusions}

The obtained calculation results indicate the energy-saving role of multi-pipe thermal insulation in heat transport. Inserting six heating pipes in common thermal insulation contributes to the reduction of heat losses, and thus to the reduction of pollutants emitted into the atmosphere resulting from heat losses. The location of many heating pipes in a common thermal insulation also reduces the material consumption of thermal insulation in multi-pipe insulations as compared to single pipes. It should be noted here that each action towards energy-efficient heat transport leads to the improvement of the quality of the environment and reduction of the operating costs of the heat source.

\section{ACKNOWLEDGEMENT}

This publication was financed within the project BUT InterAcademic Partnerships (PPI/APM/2018/1/00033/U/001). Additionally, it was conducted within the scientific cooperation 'The possibility of the renewable energy sources usage in the context of improving energy efficiency and air quality in buildings and civil constructions' between BUT and UCO and the science research funds at Bialystok University of Technology WZ/WB-IIS/9/2019.

\section{REFERENCES}

[1] Volkova A., et al. Methodology for the Improvement of Large District Heating Networks. Environmental and Climate Technologies 2012:19:39-45. https://doi.org/10.2478/v10145-012-0009-7

[2] Vigants G., et al. Modelling of the District Heating System's Operation. Environmental and Climate Technologies 2011:6:132-137. https://doi.org/10.2478/v10145-011-0019-x

[3] Stennikov V., et al. Optimization of the Effective Heat Supply Radius for the District Heating Systems. Environmental and Climate Technologies 2019:23:207-221. https://doi.org/10.2478/rtuect-2019-0064

[4] Rušeljuk P., et al. Factors Affecting the Improvement of District Heating. Case Studies of Estonia and Serbia. Environmental and Climate Technologies 2020:24(3):521-533. https://doi.org/10.2478/rtuect-2020-0121

[5] Pourbozorgi Langroudi P., Weidlich I. Applicable Predictive Maintenance Diagnosis Methods in Service-Life Prediction of District Heating Pipes. Environmental and Climate Technologies 2020:24(3):294-304. https://doi.org/10.2478/rtuect-2020-0104 
[6] Al-Barqawi H., Zayed T. Infrastructure Management: Integrated AHP/ANN Model to Evaluate Municipal Water Mains' Performance. Journal of Infrastructure Systems 2008:14(4):305-318. https://doi.org/10.1061/(ASCE)10760342(2008)14:4(305)

[7] Pakere I., et al. Climate Index for District Heating System. Environmental and Climate Technologies 2020:24:406418. https://doi.org/10.2478/rtuect-2020-0024

[8] Kondrateva O., Myasnikova E., Loktionov O. Analysis of the Climatic Factors Influence on the Overhead Transmission Lines Reliability. Environmental and Climate Technologies 2020:24:3:201-214. https://doi.org/10.2478/rtuect-20200097

[9] Diaz F., Pakere I., Romagnoli, F. Life Cycle Assessment of Low Temperature District Heating System in Gulbene Region. Environmental and Climate Technologies 2020:24(2):285-299. https://doi.org/10.2478/rtuect-2020-0073

[10] Pakere I., Blumberga D. Solar Energy in Low Temperature District Heating. Environmental and Climate Technologies 2019:23(3):147-158. https://doi.org/10.2478/rtuect-2019-0085

[11] Blumberga D., et al. Empirical Model of Cost Reduction in Local DH Systems. Low Temperature Approach. Environmental and Climate Technologies 2019:23(3):190-201. https://doi.org/10.2478/rtuect-2019-0089

[12] Krawczyk D. A., Teleszewski T. J. Reduction of Heat Losses in a Pre-Insulated Network Located in Central Poland by Lowering the Operating Temperature of the Water and the Use of Egg-shaped Thermal Insulation: A Case Study. Energies 2019:12(11):2104. https://doi.org/10.3390/en12112104

[13] Nowak-Ocłoń M., Ocłoń P. Thermal and economic analysis of preinsulated and twin-pipe heat network operation. Energy 2019:193:116619. https://doi.org/10.1016/j.energy.2019.116619

[14] Bøhm B., Kristjansson H. Single, twin and triple buried heating pipes: On potential savings in heat losses and costs. International Journal of Energy Research 2005:29:1301-1312. https://doi.org/10.1002/er.1118

[15] Krawczyk D. A, Teleszewski T. J. Optimization of Geometric Parameters of Thermal Insulation of Pre-Insulated Double Pipes. Energies 2019:12(6):1012. https://doi.org/10.3390/en12061012

[16] Teleszewski T. J, Krawczyk D. A., Rodero A. Analysis of thermal insulation of pre-insulated triple pipes - preliminary numerical tests. Renewable Energy and Power Quality Journal 2020:18:522-525. https://doi.org/10.24084/repqi18.418

[17] Directive (EU) 2018/2002 of the European Parliament and of the council of 11 December 2018 amending directive 2012/27/EU on energy efficiency. Official Journal of the European Union 2018:L 328/210.

[18] Teleszewski T. J. Effect of viscous dissipation in stokes flow between rotating cylinders using BEM. International Journal of Numerical Methods for Heat \& Fluid Flow 2019:30(4):2121-2136. https://doi.org/10.1108/HFF-11-2018$\underline{0622}$

[19] Zukowski M. Forced convection heat transfer in square duct with heated and adiabatic walls at constant axial heat flux. AIP Conference Proceedings 2019:2078:1. https://doi.org/10.1063/1.5092031

[20] Brebbia C. A., Telles J. C. F., Wrobel L. C. Boundary Element Techniques-Theory and Applications in Engineering. Berlin: Springer, 1984.

[21] Babiarz B., Zięba B. Heat losses in the preinsulated district heating systems. Civil and Environmental Engineering 2012:283:5-19.

[22] European Environment Agency, Publications Office of the European Union. EMEP/EEA Air Pollutant Emission Inventory Guidebook. Luxembourg: Publications Office of the European Union, 2016.

[23] Gómez D. R., et al. Intergovernmental Panel on Climate Change (IPCC) Guidelines for National Greenhouse Gas Inventories. Volume 2, Chapter 2: Energy, Stationary Combustion. Institute for Global Environmental Strategies. Hayama, Kanagawa: Institute for Global Environmental Strategies (IGES), 2006. 